Anverel por cont of Danthe, from the geowing of the Inetitution, 1eth Itay 1831, to 30th Saptomber 1843.

\begin{tabular}{|c|c|c|c|}
\hline $\begin{array}{l}\text { Toars onding } \\
\text { soth Bept. }\end{array}$ & $\begin{array}{l}\text { Arerage number } \\
\text { of patieuts. }\end{array}$ & $\begin{array}{l}\text { Number of } \\
\text { deaths. }\end{array}$ & $\begin{array}{l}\text { Per contege of } \\
\text { deaths. }\end{array}$ \\
\hline $\begin{array}{l}1832 \\
1885 \\
1834 \\
1835 \\
1830 \\
1837 \\
1838 \\
1839 \\
1840 \\
1841 \\
1842 \\
1843\end{array}$ & $\begin{array}{l}369 \\
519 \\
562 \\
572 \\
609 \\
609 \\
617 \\
798 \\
835 \\
883 \\
943 \\
970\end{array}$ & $\begin{array}{l}87 \\
86 \\
65 \\
63 \\
60 \\
48 \\
74 \\
92 \\
69 \\
83 \\
91 \\
68\end{array}$ & $\begin{array}{r}23.58 \\
16.57 \\
11.57 \\
11.01 \\
10.84 \\
7.88 \\
11.99 \\
11.53 \\
8.26 \\
0.39 \\
9.65 \\
7.01\end{array}$ \\
\hline
\end{tabular}

At this time, the mortality is about 7 per cent. On the opening of an asylum, and for some time after, the per centrage of desths will be high, on account of the unfaroumble cases admitted from the union houses and other places. Thus, at Colney Hatch Asylum (opened in 1851), there died in 1852, 189 patients, out of an average number of 1177 , being at the rate of (about) 17 per cent.

The mortality at St. Luke's is generally between 7 and 8 per cent., very similar to that at Hanwell; though at the former hospital the cases admitted are recent, and probably curable; and at Hanwell all insane are received indiscriminately.

As illustrative of the circumstances under which death occurs more generally to the insane, I may add, that of 243 fatal cases at the Hanwell Asylum, 109 were caused by apoplexy or epilepsy, or allied diseases; 38 by pulmonary consumption; and 46 by a gradual decline and exhaustion of the vital powers, called in the clinical register "general debility". The per centage being, therefore, in the first instance named about 43 , in the second 15 , and in the third 20 per cent.

It is worthy of mention, that the insane are, as a body, not only not insusceptible to the ordinary endemic and epidemic disorders, as fevers, cholera, diarrhoa, etc., as has been asserted, but that they are especially liable to be affected by every kind of morbid intluence, however and wherever developed.

Northwoods, Bristol, September 1855.

\section{INJURY OF THE ARM, FOLLOWED BY DEATH OF THE HUMERUS: AMPUTATION: RECOVERY.}

By HENRY ALFORD, Esq., F.R.C.S., Senior Surgeon to the Taunton and Somerset Hospital.

Jонт Bвоотrinld, aged 14 years, agricultural labourer, was admitted into the Taunton and Somerset Hospital Jan. 5th, 1855. His own account of his case was as follows.

On Jan. 3rd, whilst turning a machine for cutting roots, he felt something suddenly gire way with a snap about the right shoulder; it was attended by great pain, and quickly followed by swelling of the whole upper arm. No treatment had been used but the application of stimulating liniments.

When admitted into the hospital, the whole of the upper arm was swollen, red, hot, and very tense, with a boardlike feeling to the touch; the forearm and hand were oedematous; there was considerable irritative fever, with an anxious countenance. No fracture or displacement could be discovered. Fomentations were applied to the arm; saline medicines with opiates were given; rest in bed and low diet were enjoined.

Jan. 6th. Twelve leoches were applied to the shoulder. The fomentations were continued. Calomel and opium were given every four hours.
Jan. 9th. Thare was no improvement; the arm was in. tensely hard; he had great pain, and a rery anxiones countenance; he had little or no aloep. A free incision wh made from the upper part of the shoulder to the insertion of the deltoid on the outer aspect of the arm, through the skin and subcutaneous cellular tissue; the parts cut were of almost cartilaginous hardness. The bleoding from tho wound was moderate.

This incision was followed by some diminution of the swelling and tension; but in a day or two it was obvious that suppuration was going on beneath the muscles; and a copious discharge soon took place through the wound by a small opening in the deltoid muscle. The suppuration was very great; sinuses ran deeply through and beneath the muscular structure in all directions; but, on careful examination with a probe, we were not able to touch the bone. About ten days later, a counter-opening was made at the posterior margin of the axilla, so as to establish a dependent exit for the pus as he lay on his back; and a few threads were drawn through from the upper opening.

During this time his health was rapidly giving way; the suppuration was very profuse, the whole of the upper part of the arm being burrowed with sinuses; there was great emaciation, hectic, excessive pain, increased by the slightest motion, and very little sleep. His strength was supported by beef-tea, wine, quinine, and mineral acids; and opium was given freely. Poultices and fomentations were applied to the arm.

Feb. 6th. On examining the arm, a small ulcerated opening was found at the anterior part of the shoulder, with 2 portion of bone presenting at it; this opening was enlarged to the extent of an inch, for the purpose of re moving what was supposed to be an exfoliation of dead bone, as it was felt to be moveable; but it was found to be the entire shaft of the humerus, separated at the epiphysis, with its rough edge tilted forward against the skin, and producing the ulcerated opening. On examination with a probe, the shaft of the bone was found to be denuded of periosteum as far down as the probe would reach; the articular head remained in its natural connexion with the glenoid cavity.

On the following day, Feb. 7 th, after a consultation on the case, amputation was performed at the shoulder-joint. The patient was put fully under the influence of chloroform, and complete insensibility was kept up during the whole of the operation and dressing the wound. Some difficulties occurred in the operation; it was found impossible effectually to command the subclavian artery, in consequence of the shoulder being raised above its natural position, from the separation of the humerus, and the disorganised state of the muscles of the shoulder. The large ulcerated wound where the first incision had been made prevented the making a full sized anterior flap in the usual way by transfixion; a common straight bistoury was therefore used, and a rather narrow flap made from the cracoid process and the anterior margin of the axilla to the anterior edge of this incision. The arteries were tied as divided, as it was important to avoid loss of blood as much as possible. An amputating knife was then carried behind the separated end of the humerus, and a good sized postorior flap made; the hands of an assistant following the knife, to seize the arteries. The axillary artery was immediately secured, and several others required ligature; a number of small arteries bled freely, and the structure was so softened that it often broke down under the ligature. As many as twenty ligatures were applied in the whole; and, notwithstanding every care, he must have lost from sixteen to twenty ounces of blood. When all the bleeding vessels had been secured, the head of the bone was removed from the glenoid cavity. The cartilage and synovial membrane of the head of the humerus were inflamed and altered in structure, but that of the glenoid cavity was healthy, except a small spot of the size of a split pea in the contre of the concavity. Several portions of semiosseous and cemicartilaginous matter were removed from the surface of the stump; they appeared to be the results of attempts to form 
now bone. Tho wound which had been made the previous day, where the bone projected, was in the middle of the antecior flap, and its edges were sloughy.

The patient was much prostrated sfter the operation, and there appeared some danger of his sinking; but he soon rallied, and in a fow hours was at least as well as before the operation. The stump was dressed with sutures, etc., in the ordinary way, five or six hours after the operation; two or three more small arteries required ligature.

From this time he rapidly recovered. In two or three days he was stronger and much better than he had been for some weeks before. The stump healed well and quickly; a counter-opening was required near the anterior costa of the scapula, but by this and pressure the sinuses soon healed; the ligatures came away well. He had a good appetite, slept well, lost all his bad symptoms, and at the end of a fortnight was able to sit up and walk in the hospital garden. Before leaving the hospital, he had become quite strong and stout. He was weighed twice during his recovery, to ascertain his progress: the first time, Feb. 16th, he weighed 58 lbs.; the second time, March 26th, 75 lbs.

He had a scaly roughness of the skin, somewhat like a slight degree of ichthyosis; this was much improved by warm baths; and he was kept in the hospital some time after his stump had healed, for the treatment of this affection. He was discharged from the hospital, perfectly well and strong, on May bth.

On examining the amputated arm, the humerus was found dead, and entirely denuded of periosteum, for about three-fourths of its length. An effort had been made at the lower part to separate the dead portion, and a quantity of new bone had been thrown out. The soft parts around were burrowed with sinuses in all directions, and at the upper part of the arm were almost entirely disorganised; but some attempt at reparation appears to have been made at this part also, from the portions of osseous matter deposited there, before referred to.

REMARKS. The peculiarity in this case is the extent of mischief produced by an apparently trifling cause. What was the original injury, if any? Possibly the separation of the epiphysis. But this could not be discorered when he came to the hospital, though the infiltration and swelling of the soft parts may huve obscured it. But if this injury had taken place, it does not seem to be an adequate cause for the amount and destructive character of the inflammation which followed. The boy appeared to hare been in good health at the time of the injury, and to have been free from any scrofulous or other constitutional taint: in fact, his rapid recorery from a state of extreme depression, after the amputation, is an evidence of a sound and vigorous constitution. I saw this boy a few weeks since; he was then perfectly well, and his stump quite sound.

Taunton, Sept. 25th, 1855.

\section{OBSTETRIC CASES.}

By S. D. LEES, M.D., F.R.C.P.Ed.

Case I. VaGinat Aduesions. In 1852, Mrs. P., a young woman, lately married, applied to me for advice. She had had an illegitimate child three years before, and recovered favourably, but had been unable to kneel or bend down, as something held her tight about the anus. This, since her marriage, had prevented intercourse. On examination, I found the anus and neck of the bladder drawn together by vaginal adhesion forming a round pedicle across the vagina, about an inch in thickness. A fleshy or fibrous band could have been severed by a bold cut with a bistoury; but where there was danger of producing vesical or rectovaginal fistula, a more cautious proceeding was necessary. I succeeded in passing an elastic tube round the pedicle, and, drawing it downward, I brought the cicatrix into view, and separated the parts cautiously, when the organs at once resumed their normal position, and remain so. I noticed adhesions of the os tinex to the lateral walls of the ragina, but did not disturb them. Menstruation continues, but she has not conceived.

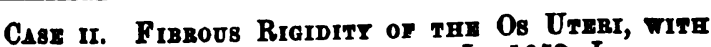
quested to visit a poor woman in labour, bJ Mr. Cooke. She was quite exhausted, had had passive hæmorrhage for some hours before his arrival, said she was dying, and obstinately refused bis examination after the first time. On my arrival, she knew me, and, after some persuasion, allowed me to examine her. I found the os uteri dilated about an inch, but without elasticity. There was a firm fibrinous ring, in place of a dilatable os uteri; delivery through it was impracticable. After some time, pains roturned, and I found laceration of the cervix large enough to admit my hand. I seized the feet, and brought them down. Mr. Cooke delirered the child, and remored the placenta without active hrmorrhage. She died from exhaustion, three hours afterwards. This woman had had a large family, and been delivered by instruments the last time.

Case iri. Placental Hemorkhage: Use or Ergor or RIE BY MIDWIVEs. This is a melancholy case, as there is every probability that the woman's life would have been saved if she had engaged proper assistance, instead of entrusting her life to an ignorant old woman.

August 17th-the day after the York meeting-Mrs. J., the wife of a small shopkeeper, aged 39 years, was in labour with her fifth child. In her last labour, she had been attended by the woman present on this occasion. She began to have pains after 8 A.M. The waters were discharged soon after 9. She kept fainting at intervals. The old woman sent for something from the druggist's, which caused her pains to strengthen. At 12 o'clock, Mrs. M., a rospectable neighbour present, saw the midwife's hands were bloody. Mrs. J. was nearly unconscious, and apparently dying. Mrs. M. insisted on further assistance, and went to Mr. Cooke's and Mr. Hunt's, who were absent. She summoned me as I was driving home. I attended without delay. I found the patient still conscious, but quite exhausted and pulseless; the skin was cold and clammy; there were no labour pains; the vagina was coated with blood, but there were no coagula, or appearance of active hæmorrhage. The head was descending in the pelvis; the os uteri, about three-fourths dilated, had a peculiar rigidity remaining, but yielded to moderate pressure. A case like this requires prompt decision and presence of mind. The head was too low for turning. To deliver with forceps, and the prospect of life fleeting with the first gush of coagula, would have been a painful predicament. I gave her very freely brandy and other stimulants; tied a broad bandage very tightly over the abdomen, to keep up pressure on the womb, and arrest internal hæmorrhage. In half an hour the skin got warm; the lips and pulse improved; she felt quite revived, and the pains returned. I now found the os utcri quite dilated, and gave a dose of ergot of rye, which acted in about twenty minutes: the child was passed rapidly through the vagina. Directing firm compression of the abdomen, I quickly detached the still-born infant; and, introducing my hand, found the uterus full of coagula, and the edge of the placenta detached. Kemoving the placenta and coagula, I kept my hand in the uterus till it was firmly contracted. The abdominal bandage was tightened up with a firm pad in the centre. Brandy, æther, etc., were given to support her; but, after half an hour's jactitation, she became placid, and quietly breathed her last, her husband and relatives at her side.

Similar symptoms, and probably the same treatment, may be familiar to many; and I should not have detailed the case except to draw attention to the use of ergot of rye by ignorant women, and its sale by respectable druggists, who know its special use, and ought not to sell it openly in the shop. The old woman got a dose of ergot, and gave it to Mrs. $J$. while there was strong rigidity of the os uteri. There was no hamorrhage previously; all the coagula seemed fresh, not as if the placenta had been detached some days.

Ashtom-under-Ljno, 8ept, 24th, 1855. 